\title{
Assessment of Levels of Occupational Exposure to UV-A and UV-C Radiation among Shielded Metal Arc Welders in Accra, Ghana
}

\author{
A. Sawyerr ${ }^{1^{*}}$, J.J. Fletcher ${ }^{2}$, J. Amoako ${ }^{3}$ and E. Sosu ${ }^{4}$ \\ ${ }^{I}$ Institute of Scientific and Technology Information (INSTI) - Council for Scientific and Industrial Research (CSIR), Ghana \\ ${ }^{2}$ University for Development Studies, Navrongo, Ghana \\ ${ }^{3}$ Health Physics and Instrumentation Centre, Radiation Protection Institute, Ghana Atomic Energy Commission, Ghana \\ ${ }^{4}$ Medical Radiation Physics Centre (MRPC), Radiological and Medical Sciences Research Institute, \\ Ghana Atomic Energy Commission, Ghana
}

\section{ARTICLE INFO}

Article history:

Received 17 June 2019

Received in revised form 10 January 2020

Accepted 27 May 2020

Keywords:

Ultraviolet radiation

Radiant exposure

Non-ionizing radiation

Safety standards

\begin{abstract}
A B S T R A C T
This study attempted to quantify the irradiance levels of ultraviolet A (UV-A) and ultraviolet $\mathrm{C}$ (UV-C) from the shielded metal arc welding (SMAW) process to welders in Accra, Ghana. Exposures were assessed via measurements, observations, and interviews. The assessments were done based on safe exposure levels prescribed by recognized international organizations such as the International Commission on Non-Ionizing Radiation Protection (ICNIRP) and the American Conference of Governmental Industrial Hygienists (ACGIH). Results from the measured UV-C irradiance levels $\mathrm{E}_{\mathrm{UV}-\mathrm{C}}$ ranged between $0.16 \pm 0.08 \mathrm{~W} / \mathrm{m}^{2}$ and $10.46 \pm 1.96 \mathrm{~W} / \mathrm{m}^{2}$ with its corresponding permissible exposure duration $t_{\max -U V-C}$ per day ranging from $5.74 \mathrm{~s}$ to $367.35 \mathrm{~s}$. The measured UV-A irradiance levels $\mathrm{E}_{\mathrm{UV}-\mathrm{A}}$ ranged from $0.88 \pm 0.03 \mathrm{~W} / \mathrm{m}^{2}$ to $23.72 \pm 6.66 \mathrm{~W} / \mathrm{m}^{2}$ with its corresponding permissible exposure duration $\mathrm{t}_{\text {max-UV-A }}$ per day ranging from $421.59 \mathrm{~s}$ to $11,363.64 \mathrm{~s}$. The obtained effective irradiance $\mathrm{E}_{\text {eff }}$ has a range of $2.08 \mathrm{~W} / \mathrm{m}^{2}$ to $28.79 \mathrm{~W} / \mathrm{m}^{2}$ with the range of permissible exposure duration $t_{\max }$ per day of $1.04 \mathrm{~s}$ to $14.40 \mathrm{~s}$. It was found that the total exposure time of the welders exceeded the permissible exposure durations and that the safety practices among the welders were unsatisfactory.
\end{abstract}

(C) 2020 Atom Indonesia. All rights reserved

\section{INTRODUCTION}

The ultraviolet (UV) radiation is an electromagnetic radiation with a wavelength shorter than that of visible light. The UV region covers the wavelength range of 100-400 $\mathrm{nm}$ and is divided into three regions [1-3]:

- UV-A (315-400 nm)

- UV-B $(280-315 \mathrm{~nm})$

- UV-C (100-280 nm)

Workers may be exposed to ultraviolet radiation (UVR) from the Sun and artificial sources such as specialized lamps and welding arcs. UV-A activates melanin pigment already present in the

\footnotetext{
* Corresponding author.

E-mail address: asawyerr001@st.ug.edu.gh

DOI: https://doi.org/10.17146/aij.2020.962
}

upper skin cells. It creates a tan that appears quickly but is also lost quickly. Furthermore, UV-A penetrates into the deeper skin layers, where connective tissue and blood vessels are affected [4]. As a result, the skin gradually loses its elasticity and starts to wrinkle. Therefore, large doses of UV-A cause premature aging. Furthermore, recent studies strongly suggest that it may enhance the development of skin cancers. The mechanisms of this UV-A damage are not fully understood, but a popular hypothesis assumes that UV-A increases oxidative stress in the cell. As with the effects on the skin, UV radiations can penetrate the eye to different depths. While UV-B and UV-C are fully absorbed by the cornea, UV-A passes through these surface layers to the lens and can cause photokeratitis (inflammation of the cornea), photoconjunctivitis (inflammation of the conjunctiva), and pterygium [5]. 
The UV-C is a lower-penetrating form of UV compared to UV-A or UV-B and is invisible to the human eye. The UV-C (short wave) ranging from 200 to $280 \mathrm{~nm}$ is the most effective wavelength range for inactivation of microorganisms with peak effectiveness near $265 \mathrm{~nm}$ [6]. UV-C exposure can also lead to ocular damage, which generally begins with photokeratitis, but can also result in photokeratoconjunctivitis. Symptoms, which depend on UV-C radiant exposure, can begin within minutes after exposure and are considered similar to a welder's burn. Symptoms can include a sensation of sand in the eyes, excessive tearing, and general discomfort around the eye ranging from moderate to severe depending on the individual [7].

The arcs associated with arc welding emits hazardous levels of UVR, and the UVR exposure could potentially injure the welders involved $[8,9]$. Arc welding produces the full spectrum of UVR. The short distance between the arc and the welder's skin may not be sufficient to absorb most of the UVC. Arc welders may therefore be at significantly increased risk of developing the health effects associated with the UV-A and UV-C emissions [8].

The purpose of this study was to quantify the irradiance levels of UV-A and UV-C from the shielded metal arc welding (SMAW), which is the most commonly employed welding method in maintenance, construction, and repair applications in factories and worksites in Ghana, received by the welders [10] and determine whether safety practices among the welders were satisfactory.

\section{THEORYICALCULATION}

\section{Calculation of permissible exposure duration}

The International Commission on NonIonizing Radiation Protection (ICNIRP) Guidelines or Exposure Limits (EL) and the American Conference of Governmental Industrial Hygienists (ACGIH) threshold limit value (TLV) represents conditions under which it is expected that nearly all individuals may be repeatedly exposed without acute adverse effects and, based upon best available evidence, without noticeable risk of delayed effects $[11,12]$. The ICNIRP guidelines or ACGIH TLV for human exposure of the eye and skin to UVR is $30 \mathrm{~J} / \mathrm{m}^{2}$ is based on $270 \mathrm{~nm}$ wavelength which is the wavelength to which the biological systems are most sensitive; it is provided for a recommended 8-hour period. When the irradiance level is known, the permissible exposure duration, $t_{\max }$, in seconds, to the spectrally weighted UVR is calculated by dividing the TLV by the irradiance level [12].
When the effective irradiance is known, the permissible exposure duration, $t_{\max }$, in seconds, to the spectrally weighted UVR is calculated by Eq. (1) $[11,12]$.

$$
t_{\text {max }}(s)=\frac{30 \frac{J}{m^{2}}}{E_{e f f} \frac{W}{m^{2}}}
$$

For UV-C radiation, the TLV for human exposure of the eye and skin is $60 \mathrm{~J} / \mathrm{m}^{2}$ at $253.7 \mathrm{~nm}$ for a daily eight-hour work shift and Eq. (2) shows its use in calculation of permissible exposure duration [13].

$$
t_{\max -U V-C}(s)=\frac{60 \frac{J}{m^{2}}}{E_{U V-C} \frac{W}{m^{2}}}
$$

In Eq. (2), $t_{\max -U V-C}=$ permissible exposure duration related to the UV-C limit in seconds; and $E_{U V-C}=$ irradiance level of UV-C.

For UV-A irradiance levels, the TLV is $10,000 \mathrm{~J} / \mathrm{m}^{2}$ [12]. The permissible exposure duration can then be found using Eq. (3) [12].

$$
t_{\text {max }-U V-A}(s)=\frac{10000 \frac{J}{m^{2}}}{E_{U V-A} \frac{W}{m^{2}}}
$$

In Eq. (3), $t_{\max -U V-A}=$ permissible exposure duration related to the UV-A limit in seconds; and $E_{U V-C}=$ irradiance level of UV-A radiation.

\section{Uncertainty Estimation}

To calculate the uncertainty of the irradiance level measurements, the various sources of uncertainty in the measurements were identified. The uncertainty from each source was estimated and finally the individual uncertainties were combined to give the overall uncertainty at any point. The standard uncertainty for the irradiance level $u(E)$ was first found by calculating the estimated standard deviation $S$, which is given by Eq. (4):

$$
S=\sqrt{\frac{\sum_{i=1}^{n}\left(x_{i}-\bar{x}\right)^{2}}{n-1}}
$$

In the equation, $x_{i}$ is the result of the $i$ th measurement and $\overline{\mathrm{X}}$ is the arithmetic mean of the $n$ results considered and $\overline{\mathrm{x}}=\sum_{\mathrm{i}}^{\mathrm{n}} \frac{\mathrm{x}_{\mathrm{i}}}{\mathrm{n}}$

Because the distribution was a normal one, $u(E)$ was calculated using Eq. (5)

$$
\mathrm{u}_{1}=\frac{\mathrm{s}}{\sqrt{\mathrm{n}}}
$$

where $n=$ number of measurements, which is equal to 3 . 
The instrument used in measuring the irradiance levels, UV254SD UV-A and UV-C light meter with datalogging SD card, had a measurement accuracy of $\pm 4 \%$ of full-scale reading, and read to the smallest division or unit of 0.001 [14]. Therefore, to estimate the instrument uncertainty, the smallest division is multiplied by interpolation factor of 0.5 as in Eq. (6).

$$
\text { Instrument uncertainty, } a=0.5 \times 0.001
$$

Therefore, the instrument uncertainty for the UV254SD was \pm 0.0005 . This was taken as a uniformly distributed uncertainty.

To find the standard uncertainty, Eq. (7) is used [15],

$$
u_{2}=\frac{a}{\sqrt{3}}
$$

Therefore, the standard uncertainty of the UV254SD is

$$
\begin{gathered}
u_{2}=\frac{0.0005}{\sqrt{3}} \\
=2.8868 \times 10^{-4}
\end{gathered}
$$

The combined standard uncertainty, $u_{c}$, was then found using Eq. (8)

$$
u_{c}=\sqrt{u_{1}^{2}+u_{2}^{2}}
$$

Therefore, the combined standard uncertainty of the UV-A and UV-C irradiance level is as given by Eq. (9).

$$
u_{c}=\sqrt{u_{1}^{2}+\left(2.8868 \times 10^{-4}\right)^{2}}
$$

The expanded uncertainty, $U$, at a $95 \%$ confidence level was found by multiplying the combined standard uncertainty by a coverage factor, $k=2$ [14]. Symbolically, $U=k \times u_{c}$

$$
=2 \times u_{c}
$$

The irradiance levels were written as $\bar{x} \pm U$ in the units of $\mathrm{W} / \mathrm{m}^{2}$. This reported uncertainty is based on a standard uncertainty multiplied by a coverage factor $k=2$, providing a level of confidence of approximately $95 \%$ [15].

\section{EXPERIMENTAL METHODS}

\section{Study population}

Subjects consisted of welders in the various welding industries. First, worksites or factories that used the SMAW process were identified in a preliminary survey. A total of 70 welders were identified in the various worksites and factories. The researchers sought consent from the relevant bodies, including the welders themselves, in order to carry out the assessment. Welders that gave their consent were the only ones assessed.

\section{Administration of questionnaire}

Questionnaires were administered to the welders at their workplaces. They were required to provide information regarding their ages, the years in which they started their careers as welders, the estimated number of hours of welding in a day, the number of days they performed welding tasks in a week, and how often they welded without personal protective equipment (PPE).

\section{Measurement of the UV-A and UV-C irradiance levels}

The fact that the potential for harmful effects is strongly dependent on the wavelength of the UV radiation leads to ranking the various wavelengths relative to $270 \mathrm{~nm}$, which is the wavelength to which the biological systems are most sensitive. The recommended TLV for eight-hour radiant exposure, which is applicable to both the eye and the skin, is $30 \mathrm{~J} / \mathrm{m}^{2}$ for $270-\mathrm{nm}$ radiation. For other wavelengths, whose spectral effectiveness is less than that of $270-\mathrm{nm}$ UV, the TLV is proportionately greater. For heterochromatic UV radiation, the $30 \mathrm{~J} / \mathrm{m}^{2}$ TLV applies to the effective spectral irradiance, which is defined in Eq. $(10)[9,16]$.

$$
E_{\text {eff }}=\sum E_{\lambda} \times S(\lambda) \times \Delta \lambda
$$

In Eq. (10), $E_{\text {eff }}=$ effective irradiance in $\mathrm{W} / \mathrm{m}^{2}$, $E_{\lambda}=$ spectral irradiance in $\mathrm{W} /\left(\mathrm{m}^{2} \mathrm{~nm}\right) ; S(\lambda)=$ relative spectral effectiveness (unitless), and $\Delta \lambda=$ bandwidth in nanometers of the calculation or measurement intervals.

The UV-A and UV-C irradiance levels are practically measured with a radiometer (survey meter) whose response to the different wavelengths is weighted by $S(\lambda)$. The UV-A and UV-C irradiance level received by each welder was obtained using a General Tools \& Instruments UV254SD UV-A and UV-C light meter with datalogging SD Card with a measurement accuracy of $\pm 4 \%$ of full-scale reading +2 digits [14]. The radiometer has a serial number of Q612737. It was designed to measure the irradiance levels of UV-A and/or UV-C light from many industrial and commercial applications including welding, UV sterilization of food, photochemical matching, erasure of electrically 
programmable read-only memory (EPROM) chips, and curing of inks. The UV254SD has the performance and features needed to satisfy the most demanding aspects of these applications. It combines the capabilities of UV-A (long waves in the $365 \mathrm{~nm}$ band) and UV-C (short waves in the $254 \mathrm{~nm}$ band) measurement in one instrument. The UV254SD comes with UV-A and UV-C probes and measures UV light intensity within two automaticallyswitched full-scale ranges: $2 \mathrm{~mW} / \mathrm{cm}^{2}$ and $20 \mathrm{~mW} / \mathrm{cm}^{2}$. Measurement of the intensity of the UV light is done by holding either the UV-A or UV-C probe by its handle, pointing the sensor with its end directed at the light source. The display reads out the intensity of the source's UV-A or UV-C light component in units of $\mathrm{mW} / \mathrm{cm}^{2}$. The UV spectrum charts from the UV254SD are shown in Fig. 1 and Fig. 2.

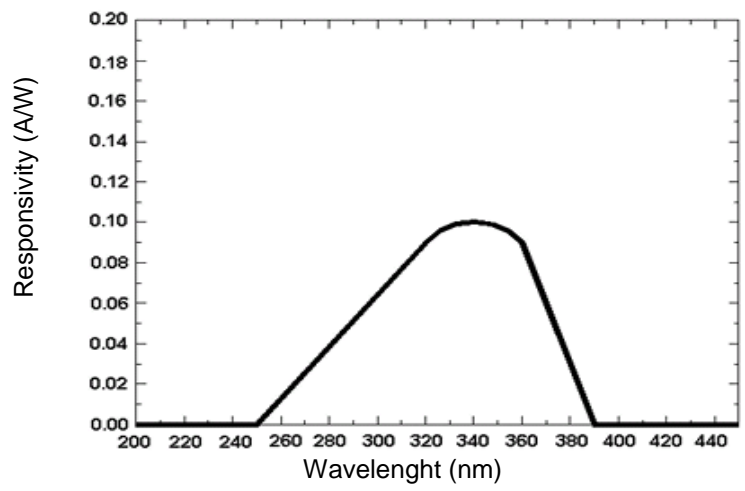

Fig. 1. UV-A sensor spectrum of UV254SD.

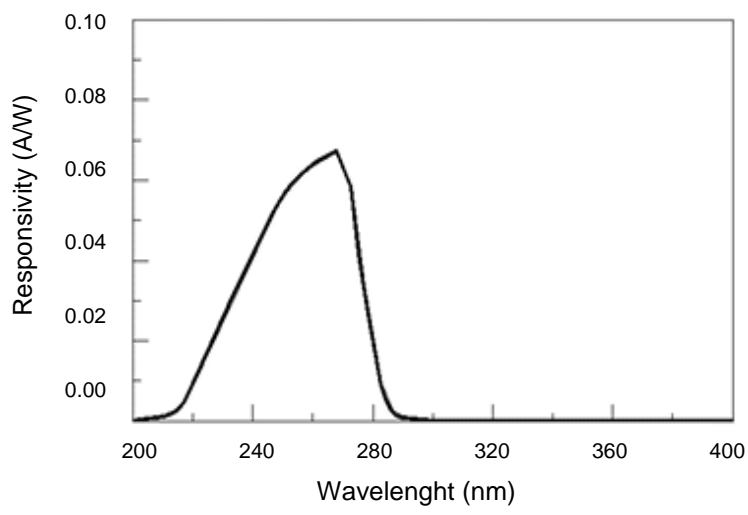

Fig. 2. UV-C sensor spectrum of UV254SD.

The probes where tested against UV lamps with known UV-A and UV-C irradiance levels at the Ghana Standards Authority (GSA) and the spectral response was confirmed to be accurate. When a filter is placed on the probe to prevent UV detection the meter recorded no readings. Information on each welding machine such as manufacturer, model, year of purchase, number of years of usage, and current used, was recorded. Measurements were made in close proximity to the head and trunk level of the welders. At least three measurements were taken for each welder and an average was taken. It was quite difficult taking measurements as these welders usually performed welding for a short time before stopping and subsequently resuming the welding task for several minutes before stopping again. The researcher needed to be vigilant to ensure the accurate reading of the irradiance levels.

Measurement of the UV-A and UV-C irradiance levels was taken with the UV-A and UV-C probe respectively. The seat of the probe was placed in the socket at the top of the UV254SD and the UV-A measurement mode was selected. The radiometer was calibrated to give the irradiance level directly and respond with a spectral weighting $S(\lambda)$ in accordance with Table 1.

Table 1. UV exposure limits and spectral weighting function $[5,18]$.

\begin{tabular}{llllllllll}
\hline $\begin{array}{l}\lambda^{\mathrm{a}} \\
(\mathrm{nm})\end{array}$ & $\begin{array}{l}\mathrm{EL}^{\mathrm{d}} \\
\left.\mathrm{m}^{-2}\right)\end{array}$ & $\begin{array}{l}(\mathrm{J} \\
\left.\mathrm{EL}^{\mathrm{d}} \mathrm{cm}^{-2}\right)\end{array}$ & $(\mathrm{mJ}$ & $\mathrm{S}(\lambda)^{\mathrm{b}}$ & $\begin{array}{l}\lambda^{\mathrm{a}} \\
(\mathrm{nm})\end{array}$ & $\begin{array}{l}\mathrm{EL}^{\mathrm{d}} \\
\left.\mathrm{m}^{-2}\right)\end{array}$ & $\begin{array}{l}(\mathrm{J} \\
\mathrm{EL}^{\mathrm{d}} \\
\left.\mathrm{cm}^{-2}\right)\end{array}$ & $\left(\mathrm{mJ}(\lambda)^{\mathrm{b}}\right.$ \\
\hline 180 & 2,500 & 250 & 0.012 & 310 & 2,000 & 200 & 0.015 \\
190 & 1,600 & 160 & 0.019 & $313^{\mathrm{c}}$ & 5,000 & 500 & 0.006 \\
200 & 1,000 & 100 & 0.030 & 315 & $1.0 \times 10^{4}$ & $1.0 \times 10^{3}$ & 0.003 \\
205 & 590 & 59 & 0.051 & 316 & $1.3 \times 10^{4}$ & $1.3 \times 10^{3}$ & 0.0024 \\
210 & 400 & 40 & 0.075 & 317 & $1.5 \times 10^{4}$ & $1.5 \times 10^{3}$ & 0.0020 \\
215 & 320 & 32 & 0.095 & 318 & $1.9 \times 10^{4}$ & $1.9 \times 10^{3}$ & 0.0016 \\
220 & 250 & 25 & 0.120 & 319 & $2.5 \times 10^{4}$ & $2.5 \times 10^{3}$ & 0.0012 \\
225 & 200 & 20 & 0.150 & 320 & $2.9 \times 10^{4}$ & $2.9 \times 10^{3}$ & 0.0010 \\
230 & 160 & 16 & 0.190 & 322 & $4.5 \times 10^{4}$ & $4.5 \times 10^{3}$ & 0.00067 \\
235 & 130 & 13 & 0.240 & 323 & $5.6 \times 10^{4}$ & $5.6 \times 10^{3}$ & 0.00054 \\
240 & 100 & 10 & 0.300 & 325 & $6.0 \times 10^{4}$ & $6.0 \times 10^{3}$ & 0.00050 \\
245 & 83 & 8.3 & 0.360 & 328 & $6.8 \times 10^{4}$ & $6.8 \times 10^{3}$ & 0.00044 \\
250 & 70 & 7 & 0.430 & 330 & $7.3 \times 10^{4}$ & $7.3 \times 10^{3}$ & 0.00041 \\
$254^{\mathrm{c}}$ & 60 & 6 & 0.500 & 333 & $8.1 \times 10^{4}$ & $8.1 \times 10^{3}$ & 0.00037 \\
255 & 58 & 5.8 & 0.520 & 335 & $8.8 \times 10^{4}$ & $8.8 \times 10^{3}$ & 0.00034 \\
260 & 46 & 4.6 & 0.650 & 340 & $1.1 \times 10^{5}$ & $1.1 \times 10^{4}$ & 0.00028 \\
265 & 37 & 3.7 & 0.810 & 345 & $1.3 \times 10^{5}$ & $1.3 \times 10^{4}$ & 0.00024 \\
270 & 30 & 3.0 & 1.000 & 350 & $1.5 \times 10^{5}$ & $1.5 \times 10^{4}$ & 0.00020 \\
275 & 31 & 3.1 & 0.960 & 355 & $1.9 \times 10^{5}$ & $1.9 \times 10^{4}$ & 0.00016 \\
$280^{\mathrm{c}}$ & 34 & 3.4 & 0.880 & 360 & $2.3 \times 10^{5}$ & $2.3 \times 10^{4}$ & 0.00013 \\
285 & 39 & 3.9 & 0.770 & $365^{\mathrm{c}}$ & $2.7 \times 10^{5}$ & $2.7 \times 10^{4}$ & 0.00011 \\
290 & 47 & 4.7 & 0.640 & 370 & $3.2 \times 10^{5}$ & $3.2 \times 10^{4}$ & 0.000093 \\
295 & 56 & 5.6 & 0.540 & 375 & $3.9 \times 10^{5}$ & $3.9 \times 10^{4}$ & 0.000077 \\
$297^{\mathrm{c}}$ & 65 & 6.5 & 0.460 & 380 & $4.7 \times 10^{5}$ & $4.7 \times 10^{4}$ & 0.000064 \\
300 & 100 & 10 & 0.300 & 385 & $5.7 \times 10^{5}$ & $5.7 \times 10^{4}$ & 0.000053 \\
$303^{\mathrm{c}}$ & 250 & 25 & 0.120 & 390 & $6.8 \times 10^{5}$ & $6.8 \times 10^{4}$ & 0.000044 \\
305 & 500 & 50 & 0.060 & 395 & $8.3 \times 10^{5}$ & $8.3 \times 10^{4}$ & 0.000036 \\
308 & 1,200 & 120 & 0.026 & 400 & $1.0 \times 10^{6}$ & $1.0 \times 10^{5}$ & 0.000030 \\
& & & & & & & \\
\hline
\end{tabular}

${ }^{a}$ Wavelengths chosen are representative; other values should be interpolated. ${ }^{b}$ Relative spectral effectiveness.

${ }^{c}$ Emission lines of a mercury discharge spectrum.

${ }^{\mathrm{d}} \mathrm{EL}$ for a monochromatic source, but also limited by a dose-rate of $10 \mathrm{~kW} / \mathrm{m}^{2}$ $\left(1 \mathrm{~W} / \mathrm{cm}^{2}\right)$ for durations greater than $1 \mathrm{~s}$ as well in order to preclude thermal effects.

It was also designed to mimic the directional sensitivity of the human skin, which was assumed to be a plane surface and follow a cosine dependence (cosine response). To determine a realistic level of exposure, the probe was held by its handle in close proximity to the welders' head or chest, which are the parts of the body of interest and where significant exposure was expected to occur. The sensor of the probe was pointed at the direction of the light source. The display then showed the irradiance level of the source's UV-A and UV-C light component in the unit of $\mathrm{mW} / \mathrm{cm}^{2}$, which was 
converted to $\mathrm{W} / \mathrm{m}^{2}$ for the purposes of this study. For every measurement, multiple sampling times of at least 30 seconds were used. Not less than three sampling times were used for each measurement. Multiple readings were logged in the memory of the radiometer and also recorded on a data sheet for each sampling time. The maximum value measured in three selected sampling times, was then chosen and averaged.

\section{RESULTS AND DISCUSSION}

\section{Types of welding machines surveyed}

There were basically two categories of welding machines, the locally manufactured ones and the imported ones, and all of them were alternating current (AC) welding machines. Out of the 70 welders studied, $51(72.86 \%)$ of them used the locally manufactured welding machines which are either using transformer oil or motor-driven and $19(27.14 \%)$ of them used imported arc welding machines.

\section{Welding machine operators}

Specific codes were used by the researchers to identify each welder in place of their names to protect their anonymity. These codes corresponded to the part of the Greater Accra Region their workshops or factories were located. The welders were between 16 and 65 years old and hailed from a variety of work fields including, among others, car maintenance/repair, advertisement, and construction sites. The average distance of welders from the welding arc was measured to be $52.71 \mathrm{~cm}$, although measurements were recorded at various distances ranging from $30 \mathrm{~cm}$ to $70 \mathrm{~cm}$.

\section{Assessment of UV-C irradiance levels from SMAW}

Figure 3 shows the UV-C irradiance $E_{U V-C}$ measured from the SMAW machine at the head/trunk level of the welders. The $E_{U V-C}$ ranged from $0.16 \pm 0.08 \mathrm{~W} / \mathrm{m}^{2}$ to $10.46 \pm 1.96 \mathrm{~W} / \mathrm{m}^{2}$. The average $E_{U V-C}$ was calculated to be $1.89 \mathrm{~W} / \mathrm{m}^{2}$. The $E_{U V-C}$ may actually be higher since the welders have the tendency for going closer to the workpiece during the strike of the arc, and irradiance is inversely proportional to the square of distance.

The corresponding permissible exposure duration $\left(t_{\max -U V-C}\right)$ per day for the $E_{U V-C}$ were calculated. The $t_{\max -U V-C}$ is intended to provide protection to workers from acute and delayed effects of UV-C exposure. Conforming to the irradiance level, the $t_{\max -U V-C}$ ranged from $5.74 \mathrm{~s}$ to $367.35 \mathrm{~s}$. The $5.74 \mathrm{~s}$ corresponded to the worst-case UV-C exposure of $10.46 \pm 1.96 \mathrm{~W} / \mathrm{m}^{2}$, and hence the $t_{\text {max } U V-C}$ increases as the irradiance level decreases. Figure 3 shows the $t_{\max -U V-C}$ correlating to the $E_{U V-C}$ of the welders. The range of $t_{\max -U V-C}$ suggests that UV-C from SMAW may actually be hazardous to the eye and skin. The average $t_{\max -U V-C}$ was found to be $66.52 \mathrm{~s}$ and the welders are likely to exceed this in a day.

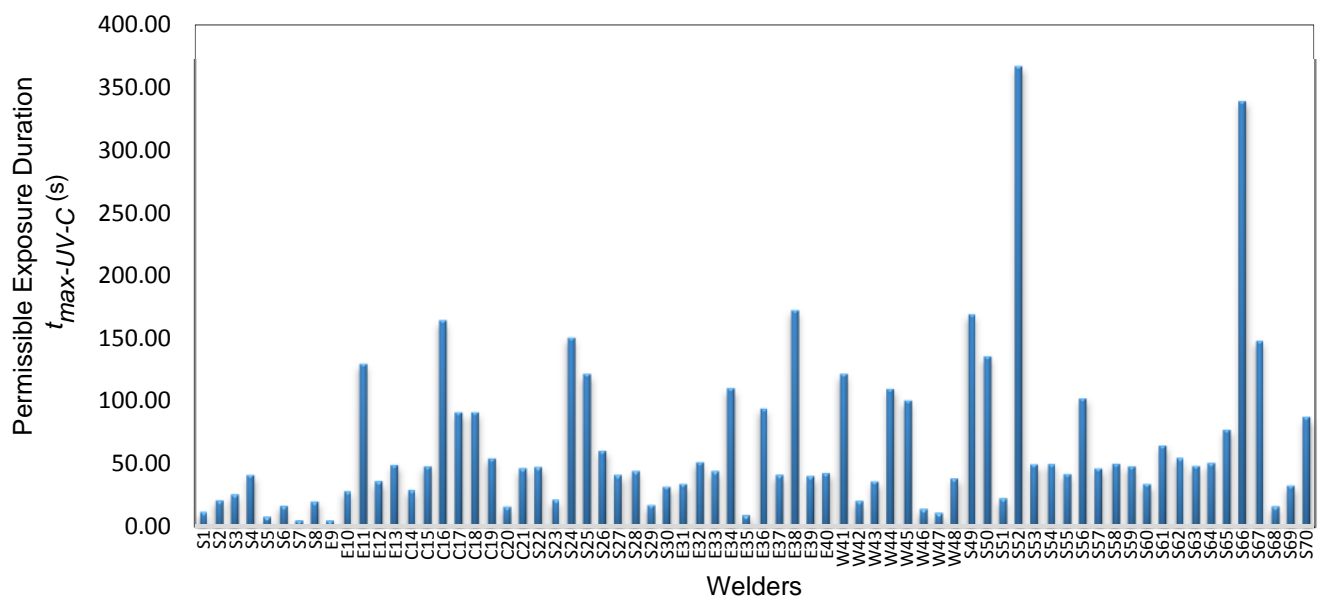

Fig. 3. Irradiance level of UV-C radiation $E_{U V-C}$ of various welders using SMAW. 


\section{Permissible exposure duration of UV-C}

The corresponding permissible exposure duration $\left(t_{\max -U V-C}\right)$ per day for the $E_{U V-C}$ were calculated. The $t_{\max -U V-C}$ is intended to provide protection to workers from acute and delayed effects of UV-C exposure. Conforming to the irradiance level, the $t_{\text {max }-U V-C}$ ranged from $5.74 \mathrm{~s}$ to $367.35 \mathrm{~s}$. The $5.74 \mathrm{~s}$ corresponded to the worst-case UV-C exposure of $10.46 \pm 1.96 \mathrm{~W} / \mathrm{m}^{2}$; hence, the $t_{\max -U V-C}$ increases as the irradiance level decreases. Figure 4 shows the $t_{\max -U V-C}$ correlating to the $E_{U V-C}$ of the welders. The range of $t_{\max -U V-C}$ suggests that UV-C from SMAW may actually be hazardous to the eye and skin. The average $t_{\max -U V-C}$ was found to be $66.52 \mathrm{~s}$ and the welders are likely to exceed this in a day.

Therefore, the total exposure time may become sufficient to cause ocular damage such as photokeratitis (inflammation of the cornea) and photokeratoconjunctivitis (inflammation of the conjunctiva, the ocular lining) or skin defects such as erythema, if the permissible exposure duration is drastically exceeded in a day, especially if the welder does not wear the appropriate welding gear or personal protective equipment (PPE). Appropriate PPE such as masks, gloves, and welding goggles have been found to diminish UV radiation levels by large amounts [17].

\section{Assessment of UV-A irradiance levels from SMAW}

The irradiance of UV-A $(315-400 \mathrm{~nm})$ radiation $E_{U V-A}$ was measured at various distances between the welders and the welding arc. The $E_{U V-A}$ ranged from $0.88 \pm 0.03 \mathrm{~W} / \mathrm{m}^{2}$ to $23.72 \pm 6.66$ $\mathrm{W} / \mathrm{m}^{2}$. The highest reading of $23.72 \pm 6.66 \mathrm{~W} / \mathrm{m}^{2}$ was taken at $\mathrm{W} 48$, a small scale metal construction welder. Other relatively high values were recorded at other metal construction workshops, S49 and S53, that were welding coal pots and gates, respectively, at the time of the measurements. The average $E_{U V-A}$ was calculated to be $10.78 \mathrm{~W} / \mathrm{m}^{2}$, and $84.29 \%$ of the measured $E_{U V-A}$ was above $5 \mathrm{~W} / \mathrm{m}^{2}$, which shows that relatively high UV-A was emitted from the SMAW. Figure 5 shows the $E_{U V-A}$ measured from the shielded arc metal welders.

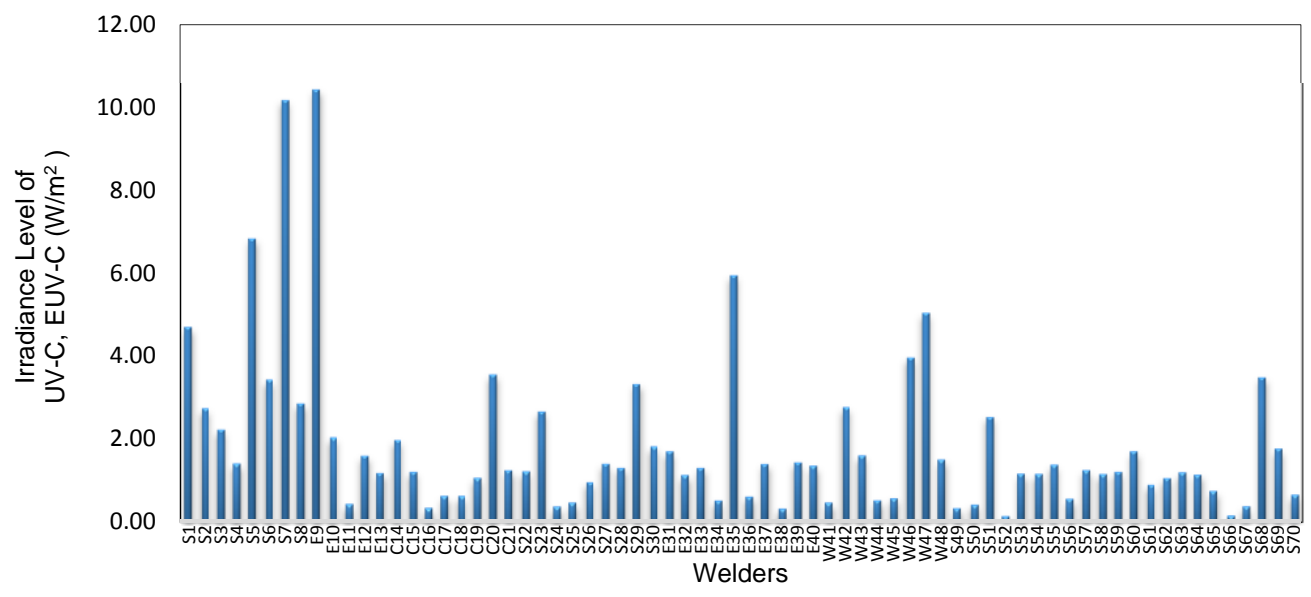

Fig. 4. Permissible exposure duration $t_{\max -U V-C}$ for corresponding $E_{U V-C}$ of welders using SMAW.

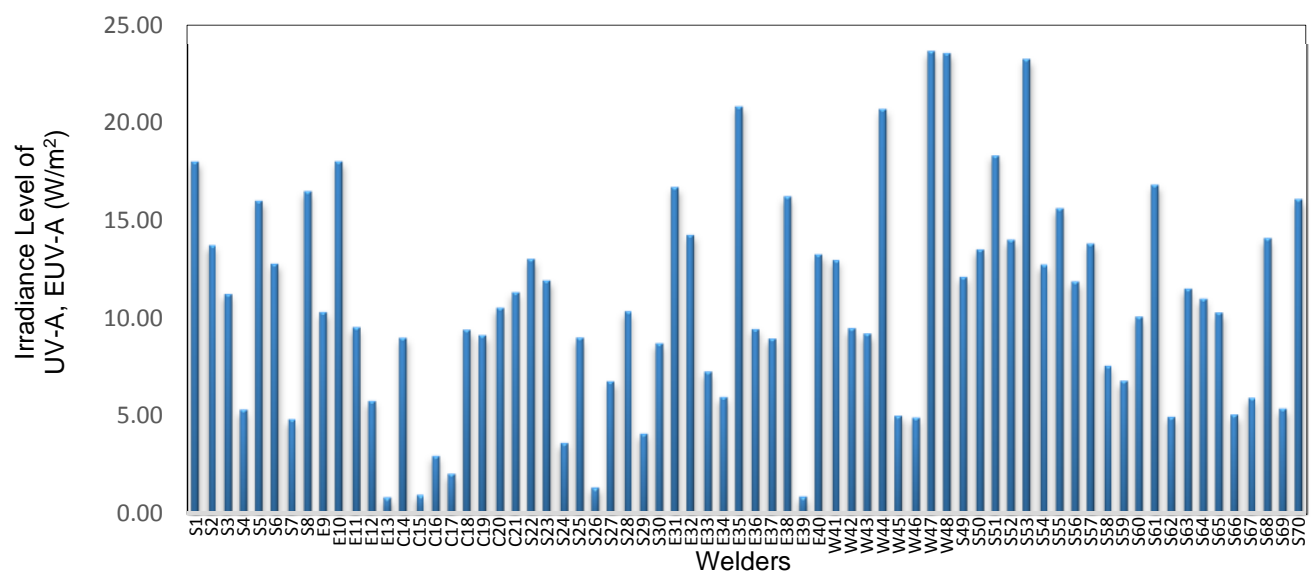

Fig. 5. Irradiance level of UV-A radiation $E_{U V-A}$ of various welders using SMAW. 


\section{Permissible exposure duration of UV-A}

Due to the relatively high $E_{U V-A}$, the permissible exposure duration $t_{\max -U V-A}$ in relation to the UV-A was calculated to determine the recommended limits for each welder. This is graphically presented in Fig. 6.

The $t_{\max -U V-A}$ had a range of $421.59 \mathrm{~s}$ to $11,363.64 \mathrm{~s}$ per day. The highest $E_{U V-A}, 23.72 \pm 6.66$ $\mathrm{W} / \mathrm{m}^{2}$, had the shortest permissible exposure duration of $7.03 \mathrm{~min}$ and the lowest $E_{U V-A}$, $0.88 \pm 0.03 \mathrm{~W} / \mathrm{m}^{2}$, had the longest permissible exposure duration of $189.39 \mathrm{~min}$. The $t_{\max -U V-A}$ has a relatively low average of 27.39 min per day but the total exposure time of the welders may be far more than this due to the nature of their work. This means that the UV-A measured from the SMAW may be sufficient to cause erythema, blistering, or prickling or burning sensations, and even cataracts and skin cancers, if the total exposure time frequently exceeds the $t_{\max -U V-A}$ in a day and the suitable PPE is not worn.

\section{Analysis of combined $E_{U V-A}$ and $E_{U V-C}$}

The combined $E_{U V-A}$ and $E_{U V-C}$ from each welder using the SMAW process was shown as $E_{\text {eff. }}$ This is not reflective of the true $E_{\text {eff, }}$, since UVB was not detected due to the detection limits of the UV254SD radiometer. Hence, it might be underestimated; it does, however, give a rough idea of the total UV radiation from the SMAW process. Also, the total permissible exposure duration of the $E_{e f f}\left(=E_{U V-A}+E_{U V-C}\right)$, namely $t_{\max }$, was calculated using Eq. (1). This was done to give an estimate of the permissible exposure duration due to the total UV radiation from the SMAW process. A comparison of the $E_{U V-A}$ and $E_{U V-C}$ from each measurement is presented in Fig. 7, while the results of the $E_{\text {eff }}$ and its corresponding $t_{\max }$ are shown in Figs. 8 and 9, respectively.

From Fig. 8, the obtained effective irradiance, $E_{\text {eff, }}$ is in the range of $2.08 \mathrm{~W} / \mathrm{m}^{2}$ to $28.79 \mathrm{~W} / \mathrm{m}^{2}$ with the range of permissible exposure duration, $t_{\max }$, of $1.04 \mathrm{~s}$ to $14.40 \mathrm{~s}$ per day (Fig. 9). This suggests that UV radiation from SMAW is actually hazardous to the eyes and skin. The average $E_{\text {eff }}$ is $12.67 \mathrm{~W} / \mathrm{m}^{2}$ and the average $t_{\max }$ per day is $3.45 \mathrm{~s}$. Although this might be an underestimation, it still suggests that UV radiation from SMAW may be hazardous to the skin and eyes.

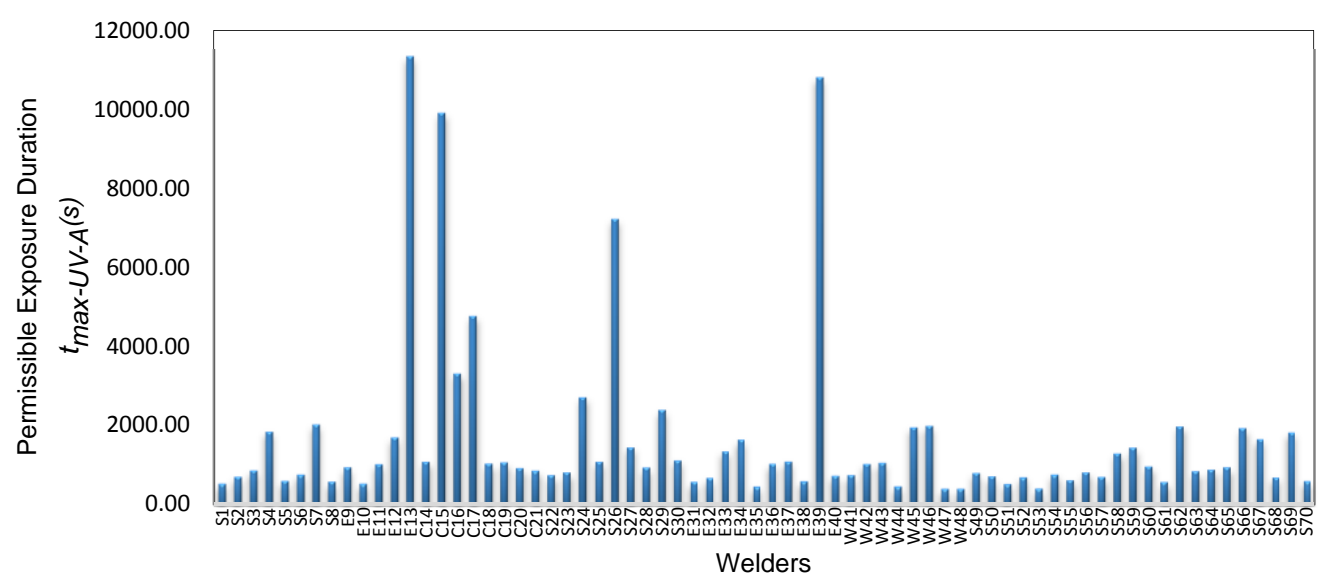

Fig. 6. Permissible exposure duration $t_{\max -U V-A}$ for corresponding $E_{U V-A}$ of welders using SMAW.

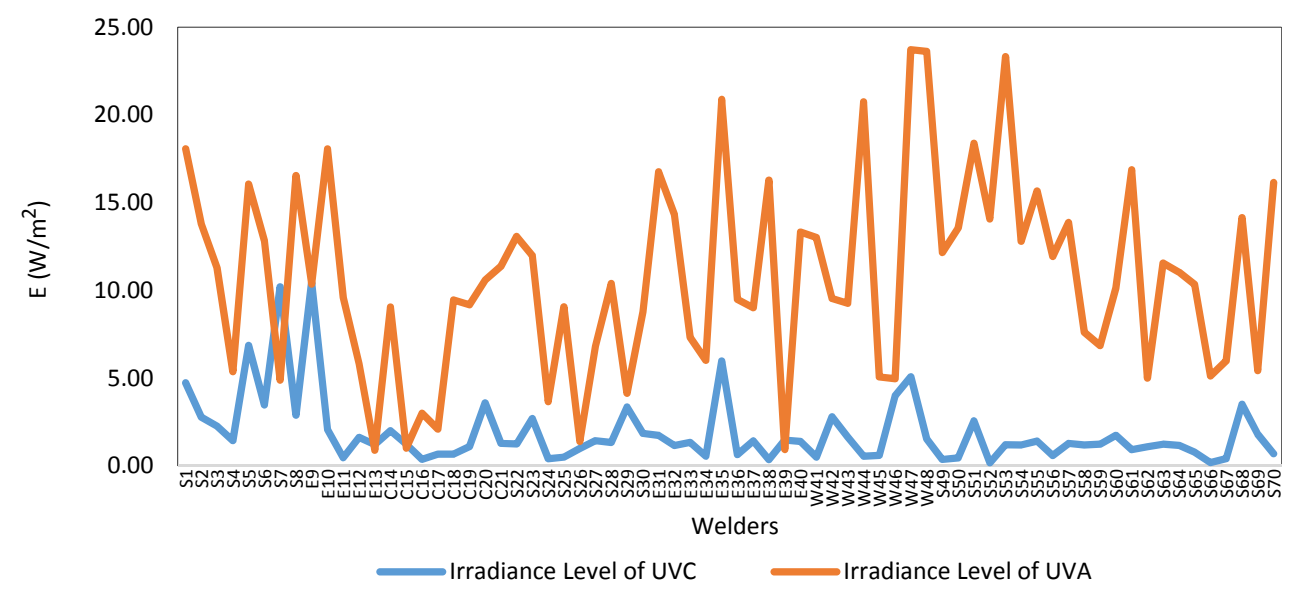

Fig. 7. Comparing UV-A and UV-C measurements from the various welders using SMAW. 


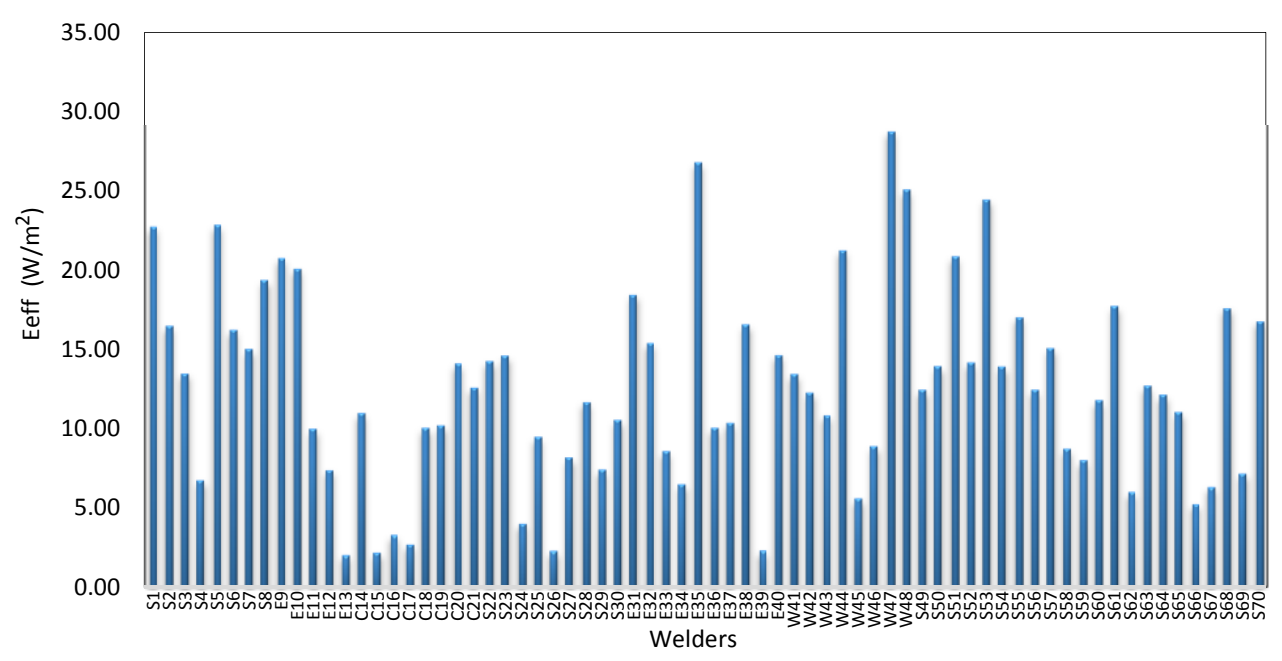

Fig. 8. $E_{\text {eff }}\left(=E_{U V-A}+E_{U V-C}\right)$ from the various welders using SMAW.

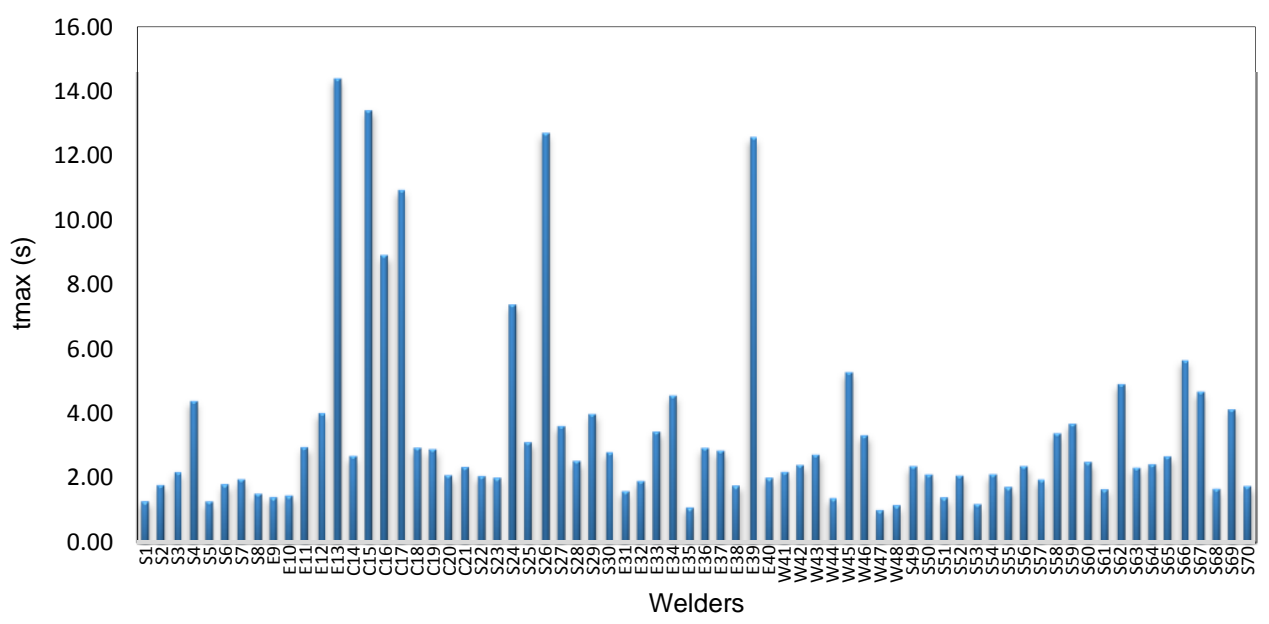

Fig. 9. Corresponding permissible exposure duration $t_{\max }$ per day for $E_{\text {eff }}$.

The UV-A and UV-C irradiance levels were measured received by welders emitting from various SMAW arcs in Ghana. Their estimated number of hours of welding in a day was analyzed from their responses as given in the questionnaire. The irradiance level from the welding UV-A and UV-C was measured with a radiometer whose response to the different wavelengths is weighted by the relative spectral effectiveness factor, $S(\lambda)$. The spectral weighting function for UV-A and UV$\mathrm{C}$ measurements and evaluation followed ACGIH and ICNIRP guidelines. Occupational health and safety guidelines, regulations, and standards have been developed in several countries and by international organizations to protect workers and the general public from potentially hazardous exposure to ultraviolet radiation. The two most widely used guidelines are virtually identical. Both the ICNIRP and the ACGIH guidelines for human exposure of the eyes and skin to UVR is $30 \mathrm{~J} / \mathrm{m}^{2}$ effective. The guidelines for UV-A and UV-C are
$10,000 \mathrm{~J} / \mathrm{m}^{2}$ and $60 \mathrm{~J} / \mathrm{m}^{2}$ respectively. The irradiance level of UV-C from the arc of SMAW ranged from $0.16 \pm 0.08 \mathrm{~W} / \mathrm{m}^{2}$ to $10.46 \pm 1.96 \mathrm{~W} / \mathrm{m}^{2}$ under the conditions of this study. The corresponding permissible exposure duration per day range was $5.74 \mathrm{~s}$ to $367.35 \mathrm{~s}$. The irradiance level of the UV-A ranged from $0.88 \pm 0.03 \mathrm{~W} / \mathrm{m}^{2}$ to $23.72 \pm 6.66 \mathrm{~W} / \mathrm{m}^{2}$ with a permissible exposure duration of $421.59 \mathrm{~s}$ to $11,363.64 \mathrm{~s}$ per day. An estimated effective irradiance $E_{\text {eff }}$ was calculated by combining the UV-A and UV-C irradiance levels from each arc of the SMAW and had a range from $2.08 \mathrm{~W} / \mathrm{m}^{2}$ to $28.79 \mathrm{~W} / \mathrm{m}^{2}$ with the corresponding permissible exposure duration, $t_{\max }$, per day ranging from $1.04 \mathrm{~s}$ to $14.40 \mathrm{~s}$. Since the welders total exposure time may exceed the permissible per-day exposure duration, multiplying their total time with the irradiance levels will greatly exceed the recommended guidelines. This suggests that UV radiation from SMAW arc welding may actually be hazardous to the eyes and skin. Comparing the 
irradiance levels from SMAW in this research to that conducted by [17] in Taiwan suggests that UVR from SMAW arc welding is actually hazardous to the eyes and skin. They had an effective irradiance at $50 \mathrm{~cm}$ from the arc of SMAW in the range of 33.1 to $311.0 \mu \mathrm{W} / \mathrm{cm}^{2}$ with a permissible exposure time per day of 9.6 to $90.6 \mathrm{~s}$ while the results of this study suggests the estimated effective irradiance at various distances ranges from $2.08 \mathrm{~W} / \mathrm{m}^{2}$ to $28.79 \mathrm{~W} / \mathrm{m}^{2}$ with a permissible exposure duration of $1.04 \mathrm{~s}$ to $14.40 \mathrm{~s}$.

From the analysis of the questionnaire administered, most of the welders worked six days a week and above 7 hours a day. About $81.43 \%$ of the welders stated they did not take any leave of absence in a year and sometimes only rested on public holidays. Most of the welders ( $80 \%$ ) attested to the fact that they sometimes weld without welding goggles, stating that the nature of some works do not permit them to, and it is possible that most of these goggles had an inappropriate shade number for the type of welding they performed since most did not take that into consideration when purchasing the gadget. Most of them confirmed that they frequently welded without protective coat, with some claiming the weather was too hot to put the coat on. This gives a general idea that safety practices among the welders was not adequate. The analysis of the open-ended questions suggested that $87.14 \%$ of them had a fair knowledge about safety although only $18.57 \%$ had attended any safety program or training before. Some stated lack of money as being the reason they could not practice adequate safety standards, indicating that the appropriate goggles were quite expensive and they could not afford those. It was also observed that symptoms such as redness of skin, prickling and burning, blisters, itchiness in the eye, cloudy vision, nausea, headache, and heart palpitations were mostly experienced only occasionally. Even so, not only should the immediate signs and symptoms be considered, but the long term effects such as skin cancers and cataracts should also be taken seriously. Since most of these symptoms are experienced by the welders and may be caused by their exposure to UV radiation and extremely low frequency $(\mathrm{ELF}) /$ medium frequency (MF) emission, there is a possibility that long term effects associated with these physical agents, especially UV radiation, may also develop. The welders must therefore take their skin and eye protection very seriously.

In this study, it was attempted to reduce recall bias to a minimum level. The subjects were requested to give their information as accurately as possible and the margin for error in reporting the welding duration was reduced by observing some of these welders thoroughly.

\section{CONCLUSION}

Two of the most widely used guidelines are virtually identical: the ICNIRP and ACGIH guidelines for human exposure of the eyes and skin to UVR is $30 \mathrm{~J} / \mathrm{m}^{2}$ effective. The guidelines for UV$\mathrm{A}$ and UV-C are $10,000 \mathrm{~J} / \mathrm{m}^{2}$ and $60 \mathrm{~J} / \mathrm{m}^{2}$ respectively. The irradiance level of UV-C from the arc of SMAW ranged from $0.16 \pm 0.08 \mathrm{~W} / \mathrm{m}^{2}$ to $10.46 \pm 1.96 \mathrm{~W} / \mathrm{m}^{2}$ under the conditions of this study. The corresponding permissible exposure duration per day ranged $5.74 \mathrm{~s}$ to $367.35 \mathrm{~s}$. The irradiance level of the UV-A ranged from $0.88 \pm 0.03 \mathrm{~W} / \mathrm{m}^{2}$ to $23.72 \pm 6.66 \mathrm{~W} / \mathrm{m}^{2}$ with a permissible exposure duration of $421.59 \mathrm{~s}$ to $11,363.64 \mathrm{~s}$ per day. Since the welders total exposure time may exceed the permissible exposure duration per day, multiplying their total time with the irradiance levels will greatly exceed the recommended guidelines. This suggests that UV radiation from shielded metal arc welding may actually be hazardous to the eyes and skin.

\section{REFERENCES}

1. E. Lastowiecka-Moras, J. Bugajska and B. Młynarczyk, Int. J. Occup. Saf. Ergon. 20 (2014) 639.

2. E.S. Lee, S.Y. Park and S.D. Ha, Food Sci. Technol. Int. 22 (2016) 213.

3. H. Moshammer, S. Simic and D. Haluza, Int. J. Environ. Res. Public Health 13 (2016) 1041.

4. F. Wang, N.R. Smith, B.A.P. Tran et al., JAMA Dermatol. 150 (2014) 401.

5. J.C.S. Yam and A.K.H. Kwok, Int. Ophthalmol. 34 (2014) 383.

6. J.M. Herndon, R.D. Hoisington and M. Whiteside, J. Geography Environ. Earth Sci. Int. 14 (2018) 1.

7. S. Indini, Esposizione Occupazionale A Radiazioni Solari Ultraviolette E Carcinoma Cutaneo/ Occupational Exposure to Solar Ultraviolet Radiation and Skin Cancer, Updating Medicina Del Lavoro (2018).

8. S. Bauer, A. Barlier-Salsi, M. Borra et al., J. Phys. Commun. 2 (2018) 477.

9. A. Rybczyński, A. Wolska, M. Wisełka et al., Energies 12 (2019) 1.

10. E.A. Gyasi, P. Kah and J. Martikainen, International Journal of Development and Sustainability 3 (2014) 1782.

11. G. Dibowski and K. Esser, Saf. Health Work 8 (2017) 237. 
12. D.H. Sliney, D.W. Gilbert II and T. Lyon, J. Occup. Environ. Hyg. 13 (2016) 413.

13. SCHEER, Opinion on Biological effects of $U V-C$ radiation relevant to health with particular reference to UV-C lamps. Scientific Committee on Health, Environmental and Emerging Risks, European Commission (2017).

14. Anonymous, UV254SD UVA and UVC Light Meter with Datalogging SD Card. https://www.generaltools.com/uva-uvc-light- meter-with-excel-formatted-data-logging-sdcard-and-k-j-port? _ SID $=\mathrm{U}$. Retrieved in April (2015).

15. A. Possolo, Simple Guide for Evaluating and Expressing the Uncertainty of NIST Measurement Results. NIST Technical Note 1900 (2015).

16. M. Masili, H. Schiabel and L. Ventura, Rad. Protec. Dos. 164 (2015) 435.

17. C.Y. Peng, H.H. Liu, C.P. Chang et al., Health Phys. 93 (2007) 101. 